\title{
Dinero y mundo popular, reflexiones para una sociología del dinero en Latinoamérica
}

\author{
Felipe González ${ }^{1}$ \\ Post-doctorado, Universidad Central de Chile, Santiago de Chile, Chile \\ felipe.gonzalez@ucentral.cl
}

\section{Wilkis, Ariel. Las sospechas del dinero. Moral y economía en la vida popular. Buenos Aires: Paidós, 2013}

La crisis financiera de Estados Unidos en el 2007 tuvo un efecto remecedor en el mundo y en las ciencias sociales, y desató un sostenido interés por las finanzas, la deuda y el dinero en general. Este interés se materializó en el intento de abrir la "caja negra" de las finanzas (MacKenzie and Millo 2008; Langley 2010) y entender mejor las formas de acumulación del capitalismo financiero (Erturk et al. 2008; Krippner 2005). La sociología económica y la economía política se arrojaron a comprender cómo es que este dinero tecnologizado y virtual se reproduce y circula a través de complicados cálculos y fórmulas que descomponen los atributos de las mercancías (derivados), las agrupan en nuevos instrumentos de inversión, les asignan una prima por riesgo, y las tranzan en tiempo real a través del globo. En este contexto, la sociología y la antropología han ofrecido en los últimos años nuevas interpretaciones acerca de la naturaleza o vida social del dinero (Ganßmann 2012; Nelms and Maurer 2014; Esposito 2011; Gregory 2012; Dodd 2014).

Es interesante ver que este movimiento colectivo ha tenido una contraparte importante en países latinoamericanos, aunque con matices y preocupaciones distintas que nos hace pensar en la existencia de algo así como una emergente sociología del dinero latinoamericana. Atendiendo a los desarrollos políticos y económicos de la última década, científicos sociales han estudiado las múltiples

1 Doctor en Economía y Ciencias Sociales.

cc) (i) Este trabajo está bajo la licencia Creative Commons Attribution 3.0

¿Cómo citar este artículo? / How to quote this article?

González, Felipe. «Dinero y mundo popular, reflexiones para una sociología del dinero en Latinoamérica». Sociedad y economía, No. 31 (julio - diciembre 2016): 263-271. 
prácticas y lógicas de cálculo asociadas a la adquisición, atesoramiento y circulación del dólar en Argentina (Luzzi 2013); las complejas prácticas financieras y cálculos económicos llevados a cabo por mujeres en las zonas rurales de México (Villareal 2014; Angulo 2014); o las formas de cálculo y prácticas asociadas al uso de tarjetas de crédito emitidas por casas comerciales en Chile (Barros 2011; González 2015). En algunos casos, estas prácticas aparecen como constitutivas de procesos institucionales que toman lugar a escalas nacionales tales como la economía solidaria en Ecuador (Nelms 2015).

Estos trabajos no solo han mapeado la diversidad de significados del dinero, sino también han caracterizado la multiplicidad de prácticas asociadas a la manipulación del dinero en circuitos de economía formal e informal. Con ello han derribado la imagen tradicional según la cual los sectores populares carecen de habilidades para gestionar la complejidad del dinero, matizando la distinción entre "altas" y "bajas" finanzas, y otorgando un lugar primordial a las prácticas económicas cotidianas de aquellos que son invisibles a las grandes narrativas del capitalismo financiarizado.

El libro de Wilkis se enmarca en esta literatura, y debe leerse y evaluarse en este marco de referencia. Esta reseña está organizada en dos partes. En la primera, pasaré revista brevemente a los principales mensajes del libro y esbozar sus hallazgos. La segunda parte, la dedicaré a reflexionar sobre la estrategia analítica que sigue y plantear algunas inquietudes. En particular, arriesgo reflexiones generales sobre el dinero y la vida social a la luz de la sociología económica, a propósito del mundo popular al que nos transporta el trabajo etnográfico de Wilkis.

Este libro no estudia el dinero. Más bien lo utiliza para acceder, a través de sus normas morales de circulación, a la vida colectiva del mundo popular, en particular de los habitantes de Villa Olimpia. Esto porque el dinero sirve como "...instrumento de ruptura frente a las representaciones discontinuas del mundo social" (Wilkis 2013, 175). La estrategia analítica y metodológica del libro podría resumirse entonces diciendo que el dinero tiene una suerte de "primacía analítica" a partir de la cual se puede acceder al resto de las formaciones sociales, religiosas, políticas y afectivas del mundo popular. Justamente porque el dinero "está en todos lados" o "es un hecho social total" (esto es desafiante), permitiría realizar una representación acabada de lo que Wilkis denomina el "rompecabezas del mundo popular".

Está claro, en esto Wilkis lleva la sociología de Zelizer (2002) desde Princeton a las zonas periféricas de Buenos Aires. Pero lo que se pone en duda no es solo el carácter corrosivo del dinero que hasta hace poco habían asumido los sociólogos. Pues la apuesta es que precisamente porque el dinero nos expone a dilemas morales y conflictos de todo tipo, se puede acceder a través de él y de las tensiones que engendra a la vida colectiva de las personas.

Amparado en estas ideas, el libro "rastrea" el dinero en sus múltiples expresiones, a través de las relaciones políticas, religiosas, domésticas y comerciales de Villa Olimpia; a través de las interacciones cara a cara, rumores, conversaciones, intercambios, mítines y rutinas de sus habitantes. Y con ello se aprende algo de la relación entre el dinero, la economía y el mundo popular que las concepciones tradicionales, las del "dinero sospechado" presentes en la literatura, música, 
periodismo y ciencias sociales, no permiten ver: el dinero no está ausente en la vida popular y no es solamente una fuente de degradación moral.

Siendo escueto, seis piezas constituyen el "rompecabezas del mundo popular" que nos muestra Wilkis. La primera pieza, el dinero donado, es aquel que se recibe como "don" y que por tanto enviste de autoridad moral al que lo otorga (el autor diría que "genera órdenes sociales mediante jerarquías monetarias"). Esta es una pieza fundamental del mundo popular, por cuanto la caridad, transferencias sociales y el valor del trabajo se entremezclan y son constantemente impugnadas dentro y fuera de la comunidad.

La segunda pieza del mundo popular es el dinero militado, que refiere al uso del dinero en intercambios políticos tradicionalmente impugnado -reduccionistamente- como clientelismo. El dinero militado surgió en el contexto específico de Villa Olimpia a partir de la consolidación de un "mercado político" local que circulaba "sueldos" a través de cadenas de reciprocidades en las que circulan dinero, mercancías y favores. Wilkis muestra en este sentido cómo el dinero militado se convirtió en una medida de evaluación moral que circula en rumores, una "nueva fuente de unidad y litigios morales" que impregnó la comunidad de Villa Olimpia.

La tercera pieza, el dinero sacrificado "comunica las virtudes de trascendencia frente a las virtudes materiales" (Wilkis 2013, 86). El sacrificio de bienes y/o dinero permite negar la posición de privilegio al momento de dar y distribuir, y por tanto se desmarca de otras formas de dinero. Asimismo, el dinero sacrificado no circula en cualquier dirección, sino que demanda del "receptor" el capital moral de ser "verdaderamente necesitado". El sacrificio se constituye fuente de capital moral en el espacio particular de la caridad y la vida religiosa, pero entra en competencia con otras jerarquías monetarias, especialmente con el dinero militado.

La cuarta pieza, el dinero ganado, aparece en las múltiples imputaciones que se realizan al dinero en el espacio "mercantil popular", representado en espacios tan diversos como el mercado de La Salada, el negocio construido en la casa, las apuestas ilegales (quinielas) o la venta de artículos robados. Así por ejemplo, el dinero ganado porta la virtud de la ganancia, así como también somete a las personas al escrutinio público o funda la obligación de prestar (dar fiado); o el dinero ganado obtenido en actividades ilícitas demanda esfuerzo por investir de legitimidad dichas actividades económicas.

La quinta pieza, el dinero cuidado, o dispuesto para los requerimientos del hogar y la unidad familiar, hace visible las contradicciones de la familia uniendo la economía doméstica con los afectos. De esta manera, todas las piezas de dinero confluyen en el hogar y se someten a los regímenes de opinión y sentimientos del dinero cuidado (Wilkis 2013, 126). Así, separar dinero ganado constituye dinero cuidado en forma de ahorro, y el dinero así cuidado se constituye en una unidad de medida del compromiso de los miembros de la familia.

Finalmente, el dinero prestado representa una de las piezas del rompecabezas del mundo popular moralmente más cargadas. El capital moral se convierte en este ámbito en el principal garante de confianza para llevar a cabo pequeños préstamos, acarreando un ethos de responsabilidad particular para el buen pagador. En el mundo popular que describe Wilkis, el capital moral detrás del dinero prestado tiene particular importancia, se cuida y se cultiva, porque 
permite a muchos acceder a los bienes y comodidades que su realidad les niega constantemente.

El libro sigue, a través de sus capítulos, cada una de estas piezas del "rompecabezas del mundo popular" y conecta así las historias individuales de los habitantes de Villa Olimpia, los hitos de la comunidad y los quiebres económicos de la nación en una narrativa que mantiene al lector cautivo. Muestra así, a modo de hilo conductor, que cada una de las piezas de ese "rompecabezas del mundo popular" articula un mundo social y monetario distinto, con sus propias reglas de acumulación, circulación y estatus.

El libro contiene interesantes propuestas teóricas y conceptuales que merecerían la pena ser discutidas extensamente. Sin embargo, en vez de entrar en estas discusiones conceptuales más finas, quisiera enfocarme en plantear algunas inquietudes y reflexiones respecto de los alcances teóricos, prácticos y metodológicos que tiene una investigación del dinero en el mundo popular.

Mi primera inquietud es general y versa sobre el dinero como punto de entrada a la vida colectiva del mundo popular. Como ya se ha insinuado, el libro se erige en contraposición a lo que Zelizer (2005) llama la perspectiva de los "mundos opuestos", en la cual las interacciones sociales discurrirían por un lado, y los medios de coordinación impersonales como el dinero, por otro. En ese sentido, la crítica a la versión "sospechosa" del dinero apunta también a la idea generalizada de que la monetización de economías de subsistencia corroe los valores preexistentes.

Sin embargo, la pregunta implícita que está en juego en el libro apunta también en una dirección distinta, que tiene que ver con cómo se reproduce una economía de subsistencia (el mundo popular) en un contexto monetizado. En este sentido, surge una duda metodológica y teórica acerca de si el dinero es un punto de entrada particularmente importante para entender las clases populares, más que a otros segmentos. En esto el libro no aporta muchas luces. Pues en principio tiendo a pensar que el dinero será siempre un objeto ubicuo en las relaciones sociales; el dinero se hace moralmente demandante y requiere "trabajo relacional" (Zelizer 2002) para circular, precisamente porque tiende a homogeneizar e impersonalizar los intercambios (que el dinero tenga múltiples "significados sociales" entonces me parece una consecuencia de su carácter impersonal).

Pero leyendo el libro, queda la impresión de que una serie de dilemas y estructuras sociales del "rompecabezas del mundo popular" se entienden mejor siguiendo el dinero porque las clases populares tienen dos características particulares: primero, porque en una economía altamente monetizada, la carencia de dinero y no la afluencia es el pan de cada día. La idea es simple: en contextos de precariedad, la escasez de dinero se hace sentir con todo su peso, es más doloroso y demandante, y me pregunto si es en parte por eso que el dinero (o su falta) puede entenderse en el contexto popular como un "hecho social total".

Y segundo, los sectores populares son probablemente tal vez más heterogéneos respecto de sus fuentes de ingresos, y están siempre más propensos a organizarse sobre una "economía mixta" o articulada a través de transferencias estatales y caridad, mezclada con trabajo asalariado formal e informal, autoempleo 
y en ocasiones con actividades ilícitas. Esto da la impresión de que en el mundo popular hay por definición muchas jerarquías monetarias circulando.

Esto tiene ciertas consecuencias. Si esto es así, y el dinero en el mundo popular es moralmente más demandante porque las jerarquías monetarias proliferan, ¿no tendríamos que asumir la dicotomía tradicional según la cual el mundo popular sería un espacio monetizado "a medias", donde el dinero moderno -homogéneo e impersonal- discurre en paralelo con otras formas de intercambio como la reciprocidad, caridad o la necesidad de colectivizar los recursos familiares (el dinero cuidado)? En este sentido, la pregunta más de fondo para las perspectivas culturales sobre el dinero sería ¿en qué condiciones podemos esperar que emerjan múltiples jerarquías monetarias?

La segunda inquietud apunta en esta misma dirección. Me parece importante el hecho de que Villa Olimpia aparece como un microcosmos, asemejándose más a una "comunidad" que a una "sociedad" (siguiendo la distinción de Tönnies) en la que los vecinos se conocen y ubican, se topan constantemente en las calles, la parroquia y las actividades sociales; donde hay claras figuras públicas que disputan el capital simbólico (Salcedo y el padre Suárez), y las interacciones cara a cara están a la orden del día. Me pregunto si tal vez es precisamente este carácter de microcosmos en un contexto monetizado el que le otorga al dinero una mayor densidad moral y lo fragmenta en distintas piezas; y si es esto lo que lo constituye en un "laboratorio del dinero" (p. 19). Al respecto, creo que vale la pena preguntar entonces en qué medida son estas piezas del rompecabezas del mundo popular expresiones de conflictos morales asociados a jerarquías monetarias propias de Villa Olimpia y, por tanto, locales; o bien, son adjetivos generalizables y las jerarquías monetarias acá descubiertas podrían considerarse como conceptos transportables al análisis de otros espacios sociales.

La tercera y última inquietud/reflexión se relaciona con los efectos prácticos que tienen distintas visiones del dinero, la de las "sospechas del dinero" y la sociología moral de Wilkis. Al menos en la sociología económica o del dinero, nadie cuestionaría que el dinero circula a través de relaciones sociales a la vez que las constituye cargadas de contenidos morales y afectivos. Pero aunque probablemente la versión "sospechosa del dinero" haya perdido fuerza en los discursos académicos, está aún presente en los medios de comunicación y en otro tipo de discusiones públicas, como bien muestra Wilkis en el capítulo 1. Por eso, más allá de las retóricas del dinero sospechado en los discursos de izquierda o la literatura latinoamericana que se presentan en el libro, me parece interesante preguntarse a qué tipo de teorías y paradigmas darían origen las concepciones totalizantes del dinero, y cuáles de estas ideas tendrían (o han tenido) efectos performativos sobre las formas de concebir el mundo popular. Creo que esto queda esbozado en la discusión en prensa que el autor presenta en el capítulo sobre dinero donado. Pero me parece interesante pensar en concreto cuál es el tipo de conocimiento y modos de intervención que genera la versión "sospechosa" del dinero, y así entender mejor cuál es el potencial iluminador de una "sociología moral del dinero" respecto de otras versiones. En estos términos, uno de los aspectos más interesantes destacados por Wilkis es el hecho de que las clases populares aparecen clasificadas según el valor moral que se les atribuya a los usos que hacen del dinero. Considerando que las clasificaciones en definitiva 
distribuyen poder y terminan modificando el curso de vida de los "clasificados" (Fourcade and Healy 2013), ¿cuál sería entonces el efecto performativo de dichas clasificaciones más allá de las jerarquías monetarias que engendran?

\section{Referencias bibliográficas}

Angulo, Lourdes. «Prácticas financieras riesgosas para afrontar la crisis económica en los hogares: entre malabarismos con el dinero y sobreendeudamiento». Desacatos, $n^{\circ}$ 44, 2014: 51-66.

Barros, Macarena. «Prácticas financieras en torno al uso del crédito en la industria». En Destapando la Caja Negra: sociologías de los créditos de consumo en Chile, editado por José Ossandón, 113-132. Santiago de Chile: Instituto de Investigaciones en Ciencias Sociales, ICSO, 2011.

Dodd, Nigel. The Social Life of Money. Princeton: Princeton University Press, 2014.

Erturk, Ismail, Julie Froud, Sukhdev Johal, Adam Leaver and Karel Williams. Financialization at Work Key Texts and Commentary. London: Routledge, 2008.

Esposito, Elena. The Future of Futures: The Time of Money in Financing and Society. Cheltenham: Elgar, 2011.

Fourcade, Marion and Kieran Healy. «Classification Situations: Life-Chances in the Neoliberal Era». Accounting, Organizations and Society, $\mathrm{n}^{\circ}$ 38, 2013: 559-572.

Ganßmann, Heiner. Doing Money. Elementary Monetary Theory from a Sociological standpoint. London: Routledge, 2012.

González, Felipe. «Where are the Consumers? 'Real Households' and the Financialization of Consumption». Cultural Studies, Vol. 29, n 5-6, 2015: 781-806.

Gregory, Christopher. «On Money Debt and Morality: Some Reflections on the Contribution of Economic Anthropology». Social Anthropology, Vol. 20, $\mathrm{n}^{\circ} 4$, 2012: 380-396.

Krippner, Greta. «The Financialization of the American Economy». Socio-Economic Review, Vol. 3, $\mathrm{n}^{\circ}$ 2, 2005: 173-208.

Langley, Paul. The Everyday Life of Global Finance: Saving and Borrowing in Anglo-America. Oxford: Oxford University Press, 2010.

Luzzi, Mariana. «Economía y cultura en las interpretaciones sobre los usos del dólar en la Argentina». En Cultura social del dólar (Serie Sociales en debate No. 5), editado por Alejandro Kaufman y Mariana Luzzi, 11-20. Buenos Aires: Universidad de Buenos Aires, 2013.

Mackenzie, Donald, and Yuval Millo. «Performativity and the Black-Scholes Model». In Financialization at Work: Key Texts and Commentary, edited by Ismail Erturk, Julie Froud, Sukhdev Johal, Adam Leaver, and Karel Williams, 269-281. London: Routledge, 2008.

Nelms, Taylor. «The Problem of Delimitation': Parataxis, Bureaucracy, and Ecuador's Popular and Solidarity Economy». Journal of the Royal Anthropological Institute, Vol. 21, $\mathrm{n}^{\circ}$ 1, 2015: 106-126.

Nelms, Taylor, and Bill Maurer. «Materiality, Symbol, and Complexity in the Anthropology of Money». In The Psychological Science of Money, edited by Erik Bijleveld, and Henk Aarts, 37-70. New York: Springer, 2014. 
Villareal, Magdalena. «De dineros, crisis y sobreendeudamientos». Desacatos, $\mathrm{n}^{\circ}$ 44, 2014: 9-15.

Zelizer, Viviana. «The Social Meaning of Money». In Readings in Economic Sociology, edited by Nicole Biggart, 315-330. Malden (Mass.): Blackwell Publishers, 2002. DOI: $10.1002 / 9780470755679 . c h 17$

Zelizer, Viviana. The purchase of intimacy. Princeton: Princeton University Press, 2005. 